\title{
Rectal Paraganglioma
}

\author{
Tomonori Araki ${ }^{1}$, Shigeyuki Takeshita ${ }^{1}$, Hiroko Kawasaki ${ }^{1}$, Koichiro Kusumoto ${ }^{1}$, \\ Kazuyuki Ohata $^{1}$, Kazuto Shigematsu ${ }^{2}$ and Masaya Shigeno ${ }^{1}$
}

\begin{abstract}
:
A 57-year-old woman was admitted with lower abdominal pain and bloody bowel discharge. She was diagnosed with rectal tumor by colonoscopy, and a biopsy was performed. Surgery was performed, resulting in a diagnosis of rectal paraganglioma. Since recurrence was confirmed three years later, reoperation was done, and chemotherapy with cyclophosphamide, vincristine and dacarbazine (CVD) was subsequently carried out for further recurrence. After the administration of up to 15 courses of CVD, we delivered best supportive care due to disease progression. She died a year and a half after starting chemotherapy. We herein report this rare disease with a review of the relevant literature.
\end{abstract}

Key words: paraganglioma, pheochromocytoma, CVD, cyclophosphamide, vincristine, dacarbazine

(Intern Med 58: 195-199, 2019)

(DOI: 10.2169/internalmedicine.1218-18)

\section{Introdution}

Although pheochromocytoma is a well-known tumor occurring in the adrenal medulla, about $10 \%$ of cases occur in the adrenal gland sympathetic ganglia and are called paraganglioma. Paraganglioma often occur near the carotid artery or along the nerve pathway of the head and neck, and it is rare to find a primary tumor in the gastrointestinal tract, especially the rectal primary is rare. We herein report this rare disease with a review of the relevant literature.

\section{Case Report}

A 57-year-old woman visited a local doctor with a chief complaint of lower abdominal pain and bloody bowel discharge without headache, palpitation or excess sweating. She was diagnosed with rectal tumor by colonoscopy and referred to our hospital for a further examination and treatment.

At our hospital, she underwent colonoscopy again, which revealed an elevated lesion in the rectum. It was a nonepithelial, soft tumor that easily bled (Fig. 1). A biopsy was performed for the rectal tumor. The pathological findings were as follows: vesicular nesting of cells with pale eosino- philic vacuoles and blood vessel proliferation. Chromogranin A, synatopophysin and tyrosine hydroxylase were positive, supporting a diagnosis of paraganglioma. There was a clear increase in the blood catecholamine levels, which also supported the diagnosis of paraganglioma.

Lower anterior resection was performed, and the pathological findings showed a Zellballen pattern, pseudorosette formation, positivity for vascular invasion, lymph node metastasis and more than $50 \%$ of the cells were Ki-67 positive in a 200 -fold high-power field. The tumor cells were chromogranin A-, tyrosine hydroxylase- and dopamine $\beta$ hydroxylase-positive and phenylethanolamine- $\mathrm{N}$-methyltransferase (PNMT)-negative, findings that were consistent with norepinephrine-producing paraganglioma (Fig. 2).

She did not require any preoperative drug treatment, and there were no issues with the changes in the blood pressure during the operation. The postoperative course was good, and she was followed up at our hospital, but three years later, left-side abdominal aortic lymph node and right common iliac artery lymph node enlargement was observed, which was suspected of being invasion of the inferior vena cava. Para-aortic lymph node dissection and inferior vena cava excision were therefore performed. The postoperative pathology revealed metastasis of paraganglioma.

The following year, para-aortic lymphadenopathy was ob-

${ }^{1}$ Department of Gastroenterology and Hepatology, Japanese Red Cross Nagasaki Genbaku Hospital, Japan and ${ }^{2}$ Department of Pathology, Japanese Red Cross Nagasaki Genbaku Hospital, Japan

Received: March 19, 2018; Accepted: April 30, 2018; Advance Publication by J-STAGE: August 24, 2018

Correspondence to Dr. Tomonori Araki, t_araki_1109@yahoo.co.jp 

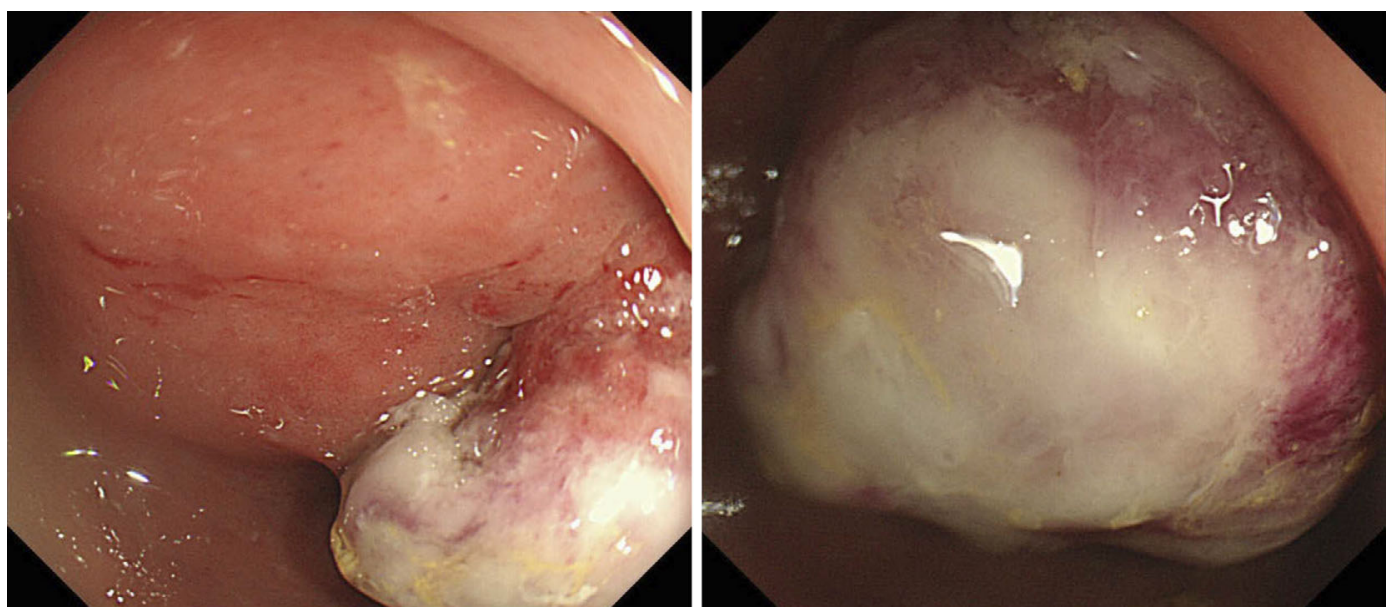

Figure 1. Colonoscopy revealed an elevated lesion in the rectum that was a non-epithelial, soft tumor that easily bled.

served, so surgical para-aortic lymph node dissection was performed. The postoperative pathology revealed metastasis of paraganglioma. The abdominal para-aortic lymphadenopathy spread from the para-aortic to the posterior part of the diaphragmatic legs and was judged to be unresectable; we therefore introduced chemotherapy.

The next month, chemotherapy with cyclophosphamide (CPA), vincristine (VCR) and dacarbazine (DTIC) (together, CVD) was started. CVD consisted of CPA at a dose of 750 $\mathrm{mg} / \mathrm{m}^{2}$ on day $1, \mathrm{VCR}$ at a dose of $1.4 \mathrm{mg} / \mathrm{m}^{2}$ on day 1 and DTIC at a dose of $600 \mathrm{mg} / \mathrm{m}^{2}$ on days $1-2$, every 3 weeks.

Although hypertensive crisis due to tumor collapse is a known risk with chemotherapy for paraganglioma, no evidence of hypertensive crisis was observed with the prophylactic administration of doxazosin mesilate. Grade 3 leukopenia and Grade 4 neutropenia were observed as hematotoxicities, but pegfilgrastim was administered from the third course as primary prevention, and pyrogenic neutropenia was not observed, so the treatment was well tolerated.

$\mathrm{CT}$ at the initial evaluation revealed stable disease per the Response Evaluation Criteria in Solid Tumors version 1.1, but disease progression was gradually recognized (1).

After the administration of up to 15 courses of CVD, we adopted best supportive care. She ultimately died a year and a half after starting chemotherapy.

\section{Discussion}

Although pheochromocytoma is a well-known tumor occurring in the adrenal medulla, about $10 \%$ of cases occur in the adrenal gland sympathetic ganglia and are called paraganglioma (2). The incidence is $2-8$ people per million per year (3). The peak occurrence is in the 20 s to 40 s, and the average age at the diagnosis is 24.9 years for hereditary cases and 43.9 years for sporadic cases (4). There is no gender difference in the incidence (5). It is found in $0.1-1 \%$ of patients with high blood pressure, and adrenal masses are found by chance in about $5 \%$ of patients $(4,6-8)$. Approxi- mately $25 \%$ of cases occur in families with hereditary syndrome, and genes such as the RET gene are known to be causative genes $(5,9)$.

The term "metastatic pheochromocytoma/paraganglioma" is used to replace "malignant pheochromocytoma/paraganglioma" in the Update on Adrenal Tumours in 2017 World Health Organization (WHO) of Endocrine Tumours (10). Paraganglioma often occur near the carotid artery or along the nerve pathway of the head and neck, and it is rare to find a primary tumor in the gastrointestinal tract, especially the rectal primary is rare (11).

Among the published reports of rare primary sites, cases of pancreas (12) and primary cases of the mesenterium (13) are found. We found only one case of rectal primary disease (11). For cases with distant metastasis, there is no established drug therapy at present. However, in Japan, CVD is administered $(14,15)$. The combined use of CVD and anthracyclines; the combined use of cisplatin and 5fluorouracil; the combined use of vepeside, carboplatin, vincristine, cyclophosphamide, adriamycine; and the combined use of temozolomide and thalidomide have been reported (16-19). Although cases of combined use with metaidodobenzylguanidine (MIBG) therapy have also been reported, the effectiveness of such a combination has not been clearly shown (20). Since cisplatin and doxorubicin enhance the uptake of MIBG in the neuroblastoma cell line, there have been reports in which MIBG therapy combined with cisplatin and doxorubicin therapy was performed, but these cases were few in number, and the effect was not obvious $(21,22) .131$ I-MIBG therapy has been reported as part of a phase II trial, with a response rate of $35 \%$ and a survival rate of 5 years of $64 \%$, but insurance approval for this regimen has not yet been granted in Japan (23).

In the present case, we observed a reduction in complications, such as diabetes and blood pressure fluctuation, with the improvement of catecholamine values due to CVD. Although the effect of prolonging overall survival is unknown by CVD, in some cases it is expected to improve symptoms 

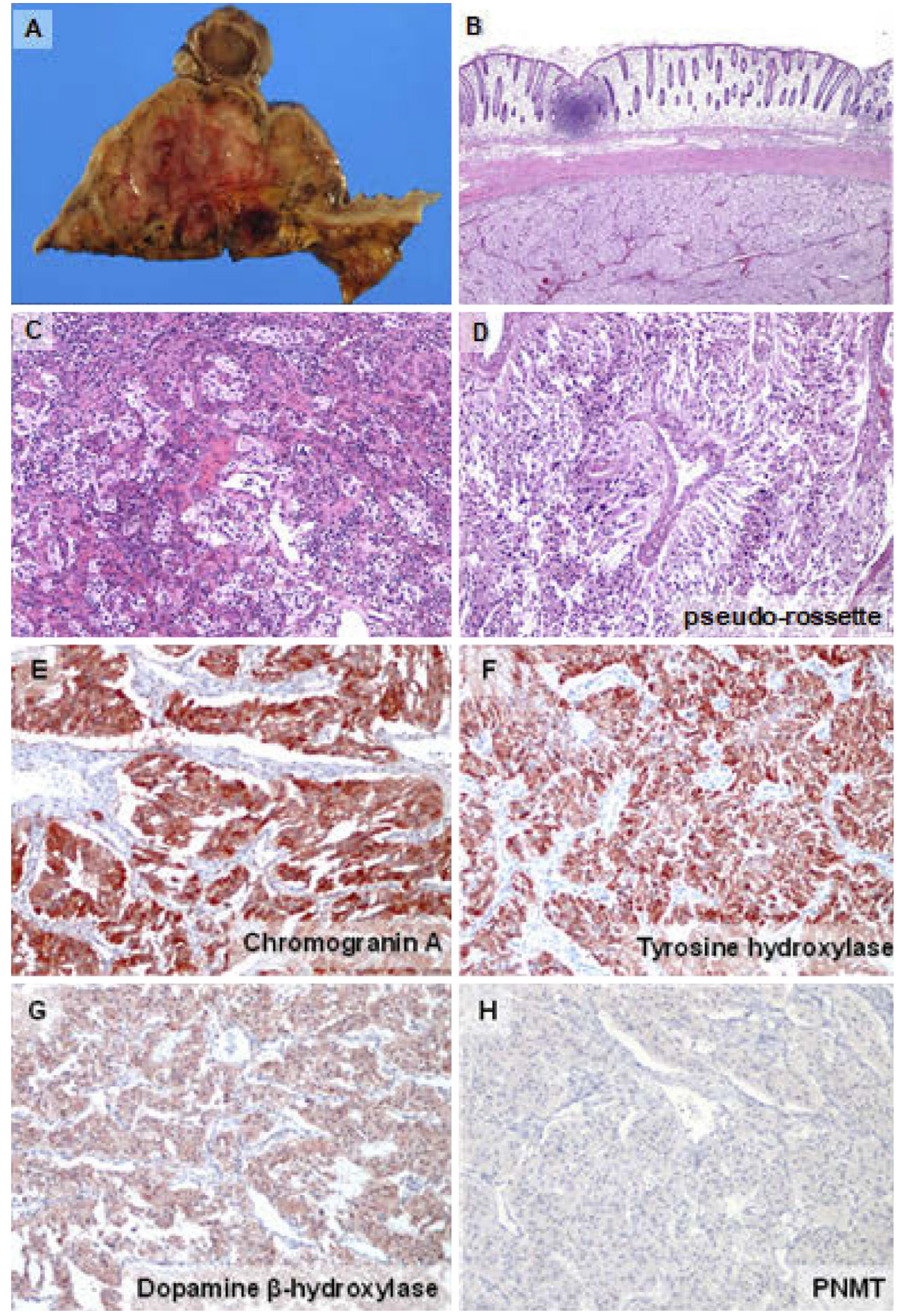

Figure 2. It shows macro specimen (A), low-power field (B), and high-power field (C-F). The pathological findings showed a Zellballen pattern (C), pseudorosette formation (D), positivity for vascular invasion, lymph node metastasis and more than $50 \%$ of the cells were Ki-67 positive at a 200-fold high-power field. The tumor cells were chromogranin A- (E), tyrosine hydroxylase- $(F)$ and dopamine $\beta$-hydroxylase-positive (G) and PNMT-negative (H), findings that were consistent with norepinephrine-producing paraganglioma.

due to tumor shrinkage (3). Although short-term effectiveness has been recognized in many case reports, the duration of the effect is assumed to be one to two years, and the long-term effect is unknown (24-26). In the present case as well, chemotherapy was able to be continued for over one year, and disease progression was reported to be somewhat ameliorated by Gonias et al. (23). Nomura et al. also described cases receiving and not receiving CVD and reported that there was no marked difference in the survival rate be- tween the two groups (27). Thus, there is no evidence that chemotherapy contributes to the improvement of the survival rate.

The classification of pheochromocytoma and paraganglioma is described in "Grading of Adrenal Pheochromocytoma and Paraganglioma (GAPP)"(Table) (28). The pathological findings of this case were moderate cellularity, vascular invasion, a Ki-67 labeling index $>3 \%$, and norepinephrine type. The histological pattern was characterized by large 
Table. Pathological Findings.

\begin{tabular}{|c|c|}
\hline Parameters & Points scored \\
\hline \multicolumn{2}{|l|}{ Histological pattern } \\
\hline Large and irregular cell nest & 1 \\
\hline Pseudorosette (even focal) & 1 \\
\hline \multicolumn{2}{|l|}{ Cellularity } \\
\hline Moderate (150-250 cells/U) & 1 \\
\hline \multicolumn{2}{|l|}{ Comedo necrosis } \\
\hline Absence & 0 \\
\hline $\begin{array}{l}\text { Vascular or capsular invasion } \\
\text { Presence }\end{array}$ & 1 \\
\hline \multicolumn{2}{|l|}{ Ki67 labelling index (\%) } \\
\hline$>3$ & 2 \\
\hline \multicolumn{2}{|l|}{ Catecholamine type } \\
\hline Norepinephrine type (NE or NECDA) & 1 \\
\hline \multirow[t]{2}{*}{ Total score } & 7 \\
\hline & enetiated type \\
\hline \multicolumn{2}{|c|}{$\begin{array}{l}\text { The pathological findings of this case were moderate cellularity, vas- } \\
\text { cular invasion, a Ki- } 67 \text { labeling index }>3 \% \text { and a norepinephrine } \\
\text { type. The histological pattern was characterized by a large and irreg- } \\
\text { ular cell nests and pseudorosettes. The total score was } 7 \text { points, and } \\
7-10 \text { points were classified as poorly differentiated type. This case } \\
\text { therefore corresponds to the poorly differentiated type according to } \\
\text { the histological grading. }\end{array}$} \\
\hline
\end{tabular}

and irregular cell nests and pseudorosettes. The total score was 7 points, and 7-10 points were classified as poorly differentiated type. This case therefore corresponds to a poorly differentiated type according to the histological grading, and a severe prognosis was presumed (29).

Although whether or not chemotherapy had a lifeprolonging effect in this case is unclear, it is possible that the side effects of chemotherapy were tolerable. There is therefore the possibility that this regimen could be useful for maintaining the quality of life without the appearance of symptoms caused by paraganglioma. This is a rare cancer, making large-scale clinical trials difficult to perform. The development of genetic testing protocols and further treatments, such as personalized medicine, is desired.

The authors state that they have no Conflict of Interest (COI).

\section{References}

1. Eisenhauer EA, Therasse P, Bogaerts J, et al. New response evaluation criteria in solid tumours: revised RECIST guideline (version 1.1). Eur J Cancer 45: 228-247, 2009.

2. Huang H, Abraham J, Hung E, et al. Treatment of malignant pheochromocytoma/paraganglioma with cyclophosphamide, vincristine, and dacarbazine: recommendation from a 22-year followup of 18 patients. Cancer 113: 2020-2028, 2008.

3. Tishler AS. Pheochromocytoma and extra-adrenal paraganglioma: updates. Arch Pathol Lab Med 132: 1272-1284, 2008.

4. Young WF Jr. Management approaches to adrenal incidentalomas. A view from Rochester, Minnesota. Endocrinol Metab Clin North
Am 29: 159-185, 2000.

5. Amar L, Bertherat J, Baudin E, et al. Genetic testing in pheochromocytoma or functional paraganglioma. J Clin Oncol 23: 88128818, 2005.

6. Sinclair AM, Isles CG, Brown I, et al. Secondary hypertension in a blood pressure clinic. Arch Intern Med 147: 1289-1293, 1987.

7. Anderson GH Jr, Blakeman N, Streeten DH. The effect of age on prevalence of secondary forms of hypertension in 4429 consecutively referred patients. J Hypertens 12: 609-615, 1994.

8. Omura M, Saito J, Yamaguchi K, Kakuta Y, Nishikawa T. Prospective study on the prevalence of secondary hypertension among hypertensive patients visiting a general outpatient clinic in Japan. Hypertens Res 27: 193-202, 2004.

9. Neumann HP, Bausch B, McWhinney SR, et al. Germ-line mutations in nonsyndromic pheochromocytoma. $\mathrm{N}$ Engl $\mathrm{J}$ Med 346: 1459-1466, 2002.

10. Lam AK. Update on adrenal tumours in 2017 World Health Organization (WHO) of endocrine tumours. Endocr Pathol 28: 213227, 2017.

11. Yu L, Wang J. Malignant paraganglioma of the rectum: the first case report and a review of the literature. World J Gastroenterol 19: 8151-8155, 2013.

12. Nonaka K, Matsuda Y, Okaniwa A, Kasajima A, Sasano H, Arai T. Pancreatic gangliocytic paraganglioma harboring lymph node metastasis: a case report and literature review. Diagn Pathol 12: 57, 2017.

13. Svajdler Mm, Bohus P, Závacký P, Vol'anská M, Repovský A, Juskanicová E. Paraganglioma of the mesenterium: a case report. Cesk Patol 43: 153-156, 2007.

14. Averbuch SD, Steakley CS, Young RC, et al. Malignant pheochromocytoma: effective treatment with a combination of cyclophosphamide, vincristine, and dacarbazine. Ann Intern Med 109: 267273, 1988.

15. Tanabe A, Naruse M, Nomura K, Tsuiki M, Tsumagari A, Ichihara A. Combination chemotherapy with cyclophosphamide, vincristine, and dacarbazine in patients with malignant pheochromocytoma and paraganglioma. Horm Cancer 4: 103-110, 2013.

16. Srimuninnimit V, Wampler GL. Case report of metastatic familial pheochromocytoma treated with cisplatin and 5-fluorouracil. Cancer Chemother Pharmacol 28: 217-219, 1991.

17. Jirari A, Charpentier A, Popescu S, Boidin P, Eisenmann B. A malignant primary cardiac pheochromocytoma. Ann Thorac Surg 68: 565-566, 1999.

18. Nakane M, Takahashi S, Sekine I, et al. Successful treatment of malignant pheochromocytoma with combination chemotherapy containing anthracycline. Ann Oncol 14: 1449-1451, 2003.

19. Kulke MH, Stuart K, Enzinger PC, et al. Phase II study of temozolomide and thalidomide in patients with metastatic neuroendocrine tumors. J Clin Oncol 24: 401-406, 2006.

20. Sisson JC, Shapiro B, Shulkin BL, et al. Treatment of malignant pheochromocytomas with 131-I metaiodobenzylguanidine and chemotherapy. Am J Clin Oncol 22: 364-370, 1999.

21. Meco D, Lasorella A, Riccardi A, Servidei T, Mastrangelo R, Riccardi R. Influence of cisplatin and doxorubicin on 125I-metaiodobenzylguanidine uptake in human neuroblastoma cell lines. Eur J Cancer 35: 1227-1234, 1999.

22. Hartley A, Spooner D, Brunt AM. Management of malignant phaeochromocytoma: a retrospective review of the use of MIBG and chemotherapy in the West Midlands. Clin Oncol (R Coll Radiol) 13: 361-366, 2001.

23. Gonias S, Goldsby R, Matthay KK, et al. Phase II study of highdose [131I]metaiodobenzylguanidine therapy for patients with metastatic pheochromocytoma and paraganglioma. J Clin Oncol 27: 4162-4168, 2009.

24. Noshiro T, Honma H, Shimizu K, et al. Two cases of malignant pheochromocytoma treated with cyclophosphamide, vincristine and 
dacarbazine in a combined chemotherapy. Endocr J 43: 279-284, 1996.

25. Edstrom Elder E, Hjelm Skog AL, Hoog A, Hamberger B. The management of benign and malignant pheochromocytoma and abdominal paraganglioma. Eur J Surg Oncol 29: 278-283, 2003.

26. Tada K, Okuda Y, Yamashita K. Three cases of malignant pheochromocytoma treated with cyclophosphamide, vincristine, and dacarbazine combination chemotherapy and $\alpha$-methyl-p-tyrosine to control hypercatecholaminemia. Horm Res 49: 295-297, 1998.

27. Nomura K, Kimura H, Shimizu S, et al. Survival of patients with metastatic malignant pheochromocytoma and efficacy of combined cyclophosphamide, vincristine, and dacarbazine chemotherapy. J Clin Endocrinol Metab 94: 2850-2856, 2009.

28. Kimura N, Takayanagi N, Takizawa N, et al. Pathological grading for predicting metastasis in phaeochromocytoma and paraganglioma. Endocr Relat Cancer 21: 405-414, 2014.

29. Kimura N, Watanabe T, Noshiro T, Shizawa S, Miura Y. Histological grading of adrenal and extra-adrenal pheochromocytomas and relationship to prognosis: a clinicopathological analysis of 116 adrenal pheochromocytomas and 30 extra-adrenal sympathetic paragangliomas including 38 malignant tumors. Endocr Pathol 16: 2332, 2005.

The Internal Medicine is an Open Access journal distributed under the Creative Commons Attribution-NonCommercial-NoDerivatives 4.0 International License. To view the details of this license, please visit (https://creativecommons.org/licenses/ by-nc-nd/4.0/).

(C) 2019 The Japanese Society of Internal Medicine Intern Med 58: 195-199, 2019 